\title{
More than Meets the Eye: A Photo-Elicitation Study of Gender (Dis)affirmation in Seven Gender Non-Conforming University Students
}

\author{
Gemma L. Witcomb, Harriet Brophy, Hilary McDermott \\ School of Sport, Exercise, and Health Sciences, Loughborough University, Leicestershire, UK \\ Email: G.L.Witcomb@lboro.ac.uk
}

How to cite this paper: Witcomb, G. L., Brophy, H., \& McDermott, H. (2019). More than Meets the Eye: A Photo-Elicitation Study of Gender (Dis)affirmation in Seven Gender Non-Conforming University Students. Psychology, 10, 1599-1614. https://doi.org/10.4236/psych.2019.1012105

Received: August 15, 2019

Accepted: September 16, 2019

Published: September 19, 2019

Copyright (c) 2019 by author(s) and Scientific Research Publishing Inc. This work is licensed under the Creative Commons Attribution International License (CC BY 4.0).

http://creativecommons.org/licenses/by/4.0/

\begin{abstract}
Clinical literature has reported on the increasing prevalence of transgender and gender diverse (TGD) people and extensively documented the high levels of discrimination and poor mental wellbeing experienced by this group. However, research that explores how gender affirmation (or otherwise) in everyday life affects an individual's lived experience is scant. This study aimed to address this crucial gap, employing photo-elicitation to collect authentic experiential accounts of how TGD students view their world. Seven TGD students took part and provided six photographs; 3 that represented salient aspects of gender affirmation and 3 that represented non-affirmation, along with explanatory textual commentary. The data were subjected to Thematic Analysis. Four themes were identified which highlight the complexities of TGD identities, as well as common sources of negativity and distress. Overall, this study provides valuable insight into gender affirmation among TGD students and offers an authentic lens alongside which other clinically-based quantitative research can be viewed. Documenting the lived experiences of TGD students is imperative if society is to move forward in understanding the complexity of gender identity in education.
\end{abstract}

\section{Keywords}

Transgender, Youth, Identity, Affirmation, Mental Health

\section{Introduction}

Increasingly, gender identity is recognised as being distinct from birth-assigned sex; that is, a person's feeling of him/her/themselves as male or female (or both/neither) does not necessarily align with the fixed, binary assignment of sex made on the basis of their secondary sexual characteristics visible at birth (Bou- 
man \& Arcelus, 2017; Richards et al., 2017). While the term "transgender" is most often used to describe those who feel their identity is more congruent with the opposite binary sex, it is in fact an umbrella term commonly used to describe any identity that falls outside of the traditional, assigned-at birth, male and female fixed binary (Davis, 2018). As such, it incorporates those who may describe themselves as non-binary, gender non-conforming, or gender-fluid, but indeed anyone who identifies as existing beyond the rigid gender roles of "male" and "female" (Richards et al., 2016; Warren et al., 2016). Of note is the fact that transgender people will differ in the extent to which they may wish to make a social or medical transition (Richards et al., 2017).

Research has shown transgender and gender diverse (TGD) individuals are coming out earlier in life (Rankin \& Beemyn, 2012) and as result there is an increased number of students identifying as TGD in higher education institutions (HEI) (Tobin \& Levi, 2013). HEIs should provide a safe and inclusive environment which promotes and supports the resilience of TGD students (McGuire et al., 2017). However, a large number of institutions have great difficulty meeting the needs of TGD students (Seelman, 2014). Mckendry and Lawrence (2017) found that $86 \%$ of TGD students sampled had faced barriers in higher education, in areas including peer relationships (56\%), identification documents (48\%) and application forms and processes (43\%). Indeed 35\% of the TGD students in this study had withdrawn from previous studies due to mental health problems (57\%), bullying and harassment (12\%), or prejudice and discrimination (10\%). The current inability of HEIs to meet TGD student needs may delegitimise these students' identity, leading to feelings of marginalisation and exclusion (Effrig et al., 2011; Pryor, 2015; Seelman, 2014).

Gender affirmation refers to an individual's gender presentation being socially recognised and supported (Nuttbrock et al., 2011; Sevelius, 2012). Understanding more about what affirms or disaffirms gender in everyday life is important in seeking to help increase affirmation to promote mental wellbeing (Russell et al., 2018). Studies with TGD adolescents have shown that many face a high risk of bullying and subsequent disaffirmation (Bradlow et al., 2017; Witcomb et al., 2019). Indeed, a recent survey of students by Stonewall (Bradlow et al., 2017) reported that TGD students experience higher levels of suicidal thoughts than their LGB (70\%) or heterosexual cisgender (25\%) counterparts. This may be because they experience higher levels of chronic psychosocial stressors, such as stigma, prejudice and discrimination (Meyer, 1995) in HEI environments. For example, TGD students have spoken about the negative impact of misgendering and the fear of being "outed" (McKendry \& Lawrence, 2017) and have asked that HEIs honour the change of names and pronouns so that their records are correct (MacNamara et al., 2017). Furthermore, University sports and athletics teams segregate students into groups of male and female (Kosciw et al., 2016) forcing TGD students to identify with a gender that is not consistent with their identity or not participate at all.

Very little research has explored and documented the lived experiences of 
TGD students, instead focusing on assessment and outcomes of those individuals who engage with services. There therefore remains a large gap in our understanding and representation of TGD identities and experiences. An understanding of their broader social affirmations and disaffirmations will inform the development of inclusive policies across HEIs.

Transgender individuals are often well versed in the telling of their story. Historically, this was particularly so for those seeking a medical transition, who had to convincingly establish their narratives, remaining within the parameters of what was medically expected from transgender people to avoid being denied gender reassignment (Borba, 2017). While retrospective narratives can be helpful, these are likely to be influenced by subsequent experiences. Thus, there is a need for data that represents the true experiences of TGD students in the here and now. Understanding more about what affirms or disaffirms gender in everyday life at university is important in seeking to help increase affirmation, and therefore, mental health.

Image-based research is becoming increasingly recognised as a methodology that can elicit rich, authentic data (Noland, 2006; Phoenix, 2010). The rising popularity of this methodology in research stems from a motivation to reduce researcher influence in the acquisition of knowledge of a particular group. This is particularly relevant in the study of TGD student experiences, where recruitment and participation have been criticised for being insensitively handled by cisgender researchers (Vincent, 2018). Thus, as a participant in photo-elicitation research, one's responses can be framed in any way that the photographer/participant chooses and provides uniquely rich information, while remaining a simplistic method (Ziller, 1990).

This aim of this study was to utilise photo elicitation to allow TGD students to define what affirms their gender and to document their lived experiences through images and accompanying narratives. It is acknowledged that participants may encompass many different identities and differ in the extent to which they have socially or medically transitioned.

\section{Method}

\subsection{Participants}

Participants were recruited via an online University LGBT+ group Facebook page, and through snowballing. Those interested in participating were invited to contact the researcher directly. Only students who identified as TGD were recruited. In total, 7 TGD students agreed to participate; 4 transmen, 2 non-binary people, and 1 transwoman (See Table 1). The research was subject to and in compliance with the requirements of the Loughborough University Ethical Advisory Committee (G04-P4) in relation to research with vulnerable participants.

\subsection{Design}

A qualitative design, using thematic analysis and photo elicitation was employed. 
Table 1. Demographics.

\begin{tabular}{|c|c|c|c|c|}
\hline Name $^{*}$ & Age & Ethnicity & Gender & Medical transition \\
\hline Michael & 21 & White British & Transman & $\begin{array}{l}\text { Due to begin in } 4 \\
\text { months }\end{array}$ \\
\hline Serena & 24 & White British & Transwoman & No \\
\hline Reza & 22 & Asian Pakistani & $\begin{array}{c}\text { Gender fluid } \\
\text { (assigned female at birth) }\end{array}$ & No \\
\hline Jake & 22 & White British & Transman & $\begin{array}{c}\text { Due to begin in the } \\
\text { next year }\end{array}$ \\
\hline Matt & 19 & White British & Transman & No \\
\hline Jess & 26 & White British & $\begin{array}{c}\text { Non-binary } \\
\text { (assigned female at birth) }\end{array}$ & $\begin{array}{l}\text { Due to begin in the } \\
\text { next year }\end{array}$ \\
\hline Isaac & 19 & White British & Transman & No \\
\hline
\end{tabular}

${ }^{*}$ Alias names given for the study.

Thematic Analysis provides a flexible and useful research tool, which can provide a rich and detailed, yet complex account of data (Braun \& Clarke, 2006). Photo elicitation was chosen as a method to elicit greater understanding of gender affirmation in TGD students than interviews/narratives alone (Frith \& Harcourt, 2007). Photographs can communicate emotion and context that can be lost in retrospective verbal accounts (Glaw et al., 2017).

\subsection{Procedure}

Participants who were interested in taking part in the study were invited to contact the researcher directly. They were sent the Participant Information Sheet detailing the study in full and the instructions for the photo elicitation task, and consent form. Participants were asked to produce six digital photographs; three of salient objects, moments or scenes that affirmed their gender under the title of "This is Me", and three of salient objects, moments or scenes that disaffirmed their gender under the title "This isn't Me". Participants were told that the photographs could be of anything and the use of a smartphone was suggested for image taking. In addition, participants were instructed to complete a written commentary for each photograph, as long or as short as they wished, providing an explanation as to why each particular photograph was taken. The photographs and commentary were submitted via email to the researcher within 3 weeks of commencing the study. While interviews are commonly used alongside photo elicitation techniques, here written commentary only was used. This was because the anonymity of the participants was of paramount concern, particularly for those who may stealth, and so online contact alone was deemed to be more appropriate.

\subsection{Analytical Approach}

Participants' photographs and accompanying commentaries were first anonymised (by giving aliases) and then analysed using Thematic Analysis (Braun \& Clarke, 2006). The commentaries were coded extensively and were continuously 
reviewed and revised and the codes were generated inductively and reflected elements of the participant's lived experience. While there is no universal approach to analysing photographic data (Harper, 1986), the scene which the photographs were communicating was factored into the analysis. This was consistent with an interpretive approach suggested by Wolcott (1994). This methodology considers the interplay of what the participant was aiming to perform in the image content, and the meaning exhibited through the commentaries. Thematic maps were created which detailed 10 initially identified themes. These were re-assessed and a final five themes were established. Respondent validation (Sparkes \& Smith, 2014) was undertaken and no changes were made.

\section{Findings}

Following analysis of the data four themes were identified:

1) The politics of presenting;

2) The transgender body;

3) Trans-erasure;

4) The power of words.

The presentation of these themes will draw on quotations from the commentaries that accompany the photographs. In the discussion of the photographs and commentaries, the pronouns used are those that are in line with the students' reported gender identity. Those who identify as non-binary or gender-fluid are referred to as "they/them/their".

\subsection{Theme 1: The Politics of Presenting}

In both the photographs and commentaries, it was clear that participants faced a constant and consistent forced negotiation of their identity in order to traverse the binary system reinforced in Higher Education.

For Serena, a transgender woman foregoing a medical transition, athletics forms a prominent aspect of her identity. The choice of photographing her athletics pitch causes Serena to reflect on her place in sport (see Figure 1(a)). She asserts that she must remain as her male birth-assigned gender on the track due to the hostility that she would face upon disclosure. Indeed this is not surprising. There are deeply fixed and uncompromising standards of what is expected of gender in University sport. Serena conceded to be viewed as her birth-identity within her sporting life. She states "I am forced to be a man to do the thing that I love". To remain safe, not only is she reduced to her birth-assigned identity and as a result forced to compete with cisgender men, but she must also continuously negotiate how she identifies in other spaces, lest this is found out by her athletics peers. Additionally, a medical transition would limit her performance goals. Having cross-sex hormone therapy (CHT), she states, would greatly reduce her athletic abilities. This leaves her facing a choice: does she prioritise her identity as a passionate athlete or her identity as a woman? This is a decision that does not have to be navigated by a cisgender student. Serena thus draws attention to 


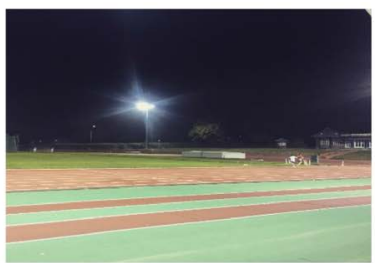

(a) Serena: This is not me

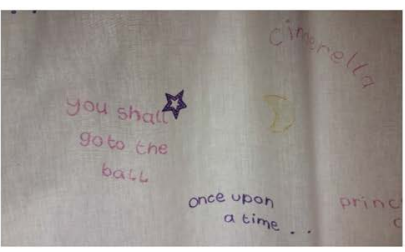

(b) Isaac: This is not me

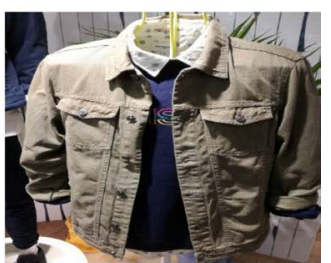

(c) Reza: This is me

Figure 1. The politics of presenting.

the many obstacles facing her gender presentation whilst at University. Competing in athletics forms part of her self-concept but it is defined by presenting as male which results in her cautiously navigating the politics of presenting as a student.

Isaac's childhood curtains (Figure 1(b)) represent gender expectations. In his home bedroom, a place designed for privacy and solitude, Isaac is physically trapped by the invasive reminder that his loved ones view him as female. Conveying typically female infant themes of princesses, Isaac must appear comfortable with this décor to remain closeted at home.

This theme was also present in the response of Michael, a transgender man who was convinced to go to the Prom by his peers. Due to his parents' refusal to allow him to wear a suit, he was forced to wear a dress. In an attempt to enjoy such a milestone of youth, Michael had to present as female. His photo depicted a group of friends enjoying their Prom but Michael did not feature in the photograph. For his peers, this was a time for celebration and excitement for the future, while Michael was imprisoned by the reminder of his birth assigned gender, made all the more painful when he was overwhelmed by compliments. $\mathrm{He}$ spent the evening placing his friends' names in the ballot box so that he would not win prom queen. Not only did Michael sacrifice his male identity and enjoyment of the Prom, he also had to actively intervene in order navigate what was an already painful experience.

Reza too reported that they felt pressure to appease their family in their dress. When shopping with their mother, Reza must conduct an obligatory scan of the women's section before heading to the men's section which features their preferred clothes (Figure 1(c)). Aware of the politics of presenting, they often act as though they are purchasing these clothes for their father, when they feel they are being scrutinised. These individual stories represent a common experience; that identity must be negotiated. That is, transgender people are required to assume alternative gender identities depending on the circumstance.

\subsection{Theme 2: The Transgender Body}

For non-binary Jess, a weightlifter (Figure 2(a)), participation granted them the freedom to sculpt the body they are denied when presenting and socialising as female. Competing began as an excuse to continue their body ambitions but then became a large part of their identity. It formed an invaluable escape from the pressures of cisnormativity. 


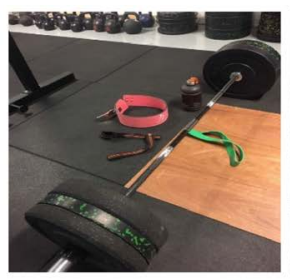

(a) Jess: This is me

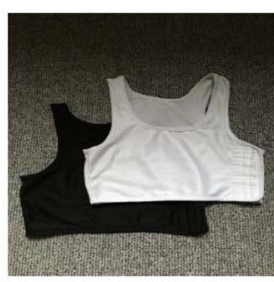

(b) Jake: This is not me

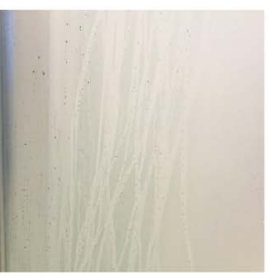

(c) Matt: This is not me

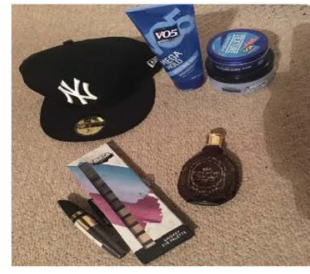

(d) Jess: This is me

Figure 2. The transgender body.

Until I discovered it I was continually striving to be smaller, to take up less space, to be slim, to be skinny. Because those were all the things I thought girls were supposed to do. But I had always found muscular bodies fascinating. I wanted big shoulders, $I$ wanted big arms. (Jess)

Transgender man Jake frequently wears binders to flatten his chest (Figure 2(b)). Binders communicate to the outer world that, like other men, Jake is flat-chested. Yet many cisgender men do not have to wear restricting garments to increase the likelihood that they are seen as male. This process reminds Jake that he is not where he wants to be; he does not want to have to wear these garments. Additionally, he is confined by the binder both physically and socially; if he removes his top in public, his gender is threatened.

Michael conceptualises his gender dysphoria as a hatred towards his body. Michael reflects that the transgender body can be the vehicle for a rather psychologically painful experience. A similar finding was reflected in Matt's commentary. For transgender people, intimate moments such as showering can result in both physical and mental vulnerability. These moments can be highly disaffirming as Matt is reminded of the physicality of his birth assigned gender. He maintains that: "showering is difficult since it means confronting my body, which is something I'm inherently uncomfortable with". Matt's use of this steamed shower cubicle indicates this may also be a highly lonely experience, and despite the steam, he cannot escape his body (Figure 2(c)).

Yet for Jess, their ability to construct their identity using makeup and hair gel represents an act of defiance to those who led them to believe they must present in a particular way (Figure 2(d)). They defy what is expected of them when they combine their love of feminine products with more typically masculine products. For Jess, these things represent all that they were taught they could not have. Their transgender body is therefore a source of empowerment.

You cannot see it very well in the photo but the perfume bottle says "women only" underneath the name-it feels like a subtle act of defiance every time that I pick it up and spray it-a refusal to conform, and a determination to continue to wear all of the things that I enjoy. (Jess)

Serena reflected on the positive aspects of identity expression. For her, outward presentations became a loop of positive feedback:

I present femininely and this makes me feel good and affirms my gender, which makes me want to present more femininely. The absence of this positivity becomes dysphoria. 
Serena also recognises the effect of failure to engage in these actions. It can be considered that these behaviours are not only adopted for affirmation, but for survival.

\subsection{Theme 3: Trans-Erasure}

Matt reflects "I don't feel like I fit into either category... I tend to put my assigned gender on forms to avoid confusion" (Figure 3(a)). This emphasises that transgender people often lie somewhere outside of the binary. Within the legal sphere, they are often compelled to affiliate with a gender not consistent with their identity. Matt's continual denial of recognition forms a fundamentally disaffirming experience.

Jake uses an image of a disabled sign to communicate that most transgender people like him use disabled facilities out of fear of confrontation (Figure 3(b)). What constitutes a deeply disaffirming experience for Jake is that these are not designed for able-bodied transgender people. Instead they are used to avoid the potentially distressing alternative. In doing so, parallels can be then drawn between transgender and disability. Despite an ongoing urge of their community to be depathologised, communal constructs communicate that they outside the norm and reinforce a medicalised view of transgender lives.

The first time that I walked into the men's toilets I felt so happy that no one questioned me, but when I saw there was no door on the cubicle my heart sunk, I was pretty embarrassed. It was horrible. (Jake)

Additionally, cisnormative structures assume most men stand while using the bathroom and the lack of doors assume men do not require privacy. As such, to avoid potential confrontation, transgender men are obliged to use bathrooms where gender is not concerned. The lack of consideration to facilities for transgender individuals may be attributed to institutional policing of gender and trans-erasure.

\subsection{Theme 4: The Power of Words}

Words can be influential on transgender experiences. Both Serena and Matt articulate the highly affirming nature of being called their correct name (Figure 4(a)). The relationships formed with those who respect their identity are highly validating of their self-concept and both participants reflect on its positive impact.

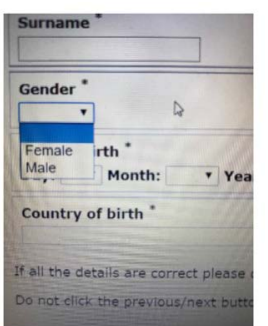

(a) Matt: This is not me

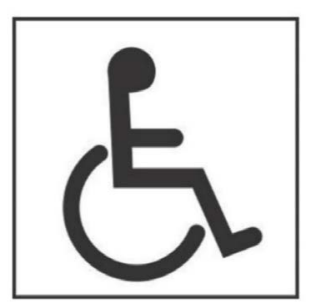

(b) Jake: This is not me

Figure 3. Trans-erasure. 


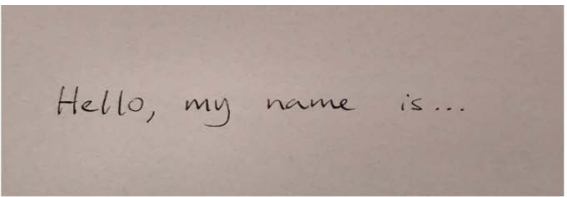

(a) Matt: This is me

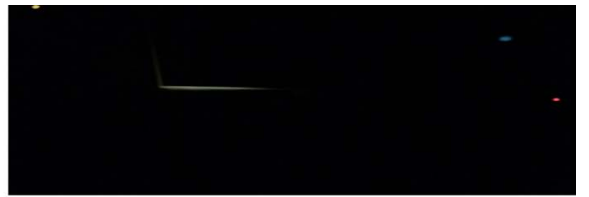

(b) Michael: This is not me

Figure 4. The power of words.

...being around people who validate and respect my identity is so powerful. Being around friends who know me as my chosen name and use the right pronouns for me make me feel so comfortable, so confident and so much happier. (Matt)

Additionally, the power of her new name helped Serena to differentiate between her previous male-informed identity and her identity as a transgender woman. Her name not only aligned with her gender but allowed her to conceptualise her journey to her current self-concept.

There are memories, male-informed actions and a male gendered psychic disposition that I associate with an old me and with my old name and there are different memories and actions and a new disposition that I associate with the person I am now. (Serena)

Yet words can embody binary-informed assumptions. Reza particularly feels misgendered when people alter their language when approaching their feminine presenting friends. The gendered conations of "mate" and "love" is a daily frustration. Similar experiences were reported by other participants and the effect of language goes beyond the frustrating. Michael's image of the night sky from his bedroom at 4 am reflects his inability to sleep (Figure $4(\mathrm{~b})$ ). He reported to be frequently met with this view as he finds disaffirming social interactions difficult to digest.

One guy made fun of how wide my hips were once, and I stayed up wondering if I could quick fix my body issue problems with a hacksaw...it hurts to be so uncomfortable in my own skin. (Michael)

While words have a transformative power for Matt and Serena, for others they are the embodiment of transphobia. Michael considers self-mutilation as a direct result of a cisgender person's unsolicited comment about his body. The extent to which transgender people feel anguish following verbal interactions should therefore never be underestimated. Furthermore, the power of words upon this sample of transgender young people highlights the powerful influence of cisgender people in the transgender self-concept and well-being.

\section{Discussion}

The aim of this study was to illuminate and understand the lived experience of TGD students using photo-elicitation as an innovative device that goes beyond verbal narratives. This was done in order to more deeply understand the gender affirming and disaffirming objects, events and experiences that are felt by this 
population. The combination of photographic and explanatory responses offered the freedom and time for the participant to contemplate how they desired to be represented. By selecting images that affirmed or disaffirmed their identity, the participants were able to powerfully self-illustrate this. Through this self-documentation, various themes prevailed which reflected both the individual's self-concept and environmental structures.

Butler (1990) emphasised how we "do" rather than inherently "be" our gender, and thus gender is in many ways performative. This study found evidence consistent with this notion when participants were given the agency to present their own experiences. The politics involved in the presentation of transgender identities was evident as a theme. When it comes to "doing" gender, TGD students had limited options and considerably restricted agency, largely associated with feeling safe within their environment. For this group of young transgender people, "doing" gender involved some risk, which they navigated alone.

A possible explanation for this common experience relates to public discourse on transgender ideals. The transgender body reflects cultural attitudes of femininity and masculinity (Borba \& Osterman, 2007). Lovelock (2016) analysed media discourse following the presence of influential transgender women within Western media. As a result, "born in the wrong body" remains the dominant narrative within societal understanding of transgender. The resulting assumption is that to access the true self, a transgender person must exclusively engage with the side of the binary associated with their gender; transgender women must be inherently feminine and transgender men must be inherently masculine. According to this perception, these traits should be reflected in the transgender person's bodily work. This may explain why many participants in this study felt they couldn't publicly access different spaces within the binary-either because they were not at a stage to pass, or because in the case of non-binary identifying people-they had no desire to fit into either and expressed a defiance in doing so. Thus, through presenting rigid transgender ideals, this discourse disregards TGD students who do not associate with either side of the binary and further ostracises many identities within the transgender community. Indeed, research with non-binary individuals has shown that they may face even greater discrimination than binary trans people and suffer even greater effects on wellbeing as a result of not "fitting" into either binary box (Thorne et al., 2018).

A closer examination of the data found that all of the participants engaged in some form of adjustment to affirm their physical body. Reasons for sculpting their body presentation varied across the sample. For some, it served to align their body with their gender, for others it was an act of defiance over societal norms. All highlighted the obstacles facing their inherently gendered body and many participants in the present study found addressing their body a difficult task. Allen (2010) has suggested that the celebration of the physicality of transgender bodies has been primarily confined to those which are resultant from surgery or hormone replacement. Thus, even in spaces designed for transgender celebration, only certain transgender bodies may take part. Nonetheless, the 
narratives demonstrate that there is no common transgender body or body experience. Each participant in this study had their own unique circumstances and unique desires regarding affirming their body. To assume that these participants were indistinguishably similar would be reducing the diversity of the experiences of all who fall under the transgender umbrella.

The analysis also yielded consistent documentation of institutional transgender exclusion and trans-erasure. From bathroom resources to legal forms, trans-erasure was seemingly pervasive and served to communicate a message that transgender people are invisible. This exclusion was felt beyond mere inconvenience and was highly isolating and disempowering. It is difficult to obtain literature on transgender history (Whitehead, 2017) meaning that any legacy is continuously policed and largely erased. Although there has been recent progression in transgender acceptance, societal attitudes still underpin which aspects of the transgender identity can be visible. Miller et al. (2017) reported that Americans were more supportive of the civil rights of transgender people, such as equal protection under the law, and less supportive of rights pertaining to their body, for example, the use of public bathrooms. This illustrates how there still remains a significant gap between policy and enacted human rights, which is relevant for Higher Education.

Language was also highlighted as an important theme within these young TGD students, with varying effects. Language can be regarded as a performative and powerful tool, motivated by underlying frames of reference (Bouman et al., 2016). With a societal frame of reference that is hostile, it is unsurprising that transgender people may receive comments on physique, such as the size of their hips as reported by one of our participants. Kenny et al. (2017) found that, in the general population, peer comments have a significantly negative effect on body image and mental health. This effect may therefore be even greater in transgender young people who may be simultaneously navigating feelings of body dysphoria, distress, and marginalisation. However, when TGD students were addressed in a positive way, such as the adoption of their correct pronouns, participants felt deeply affirmed. This has also been found in other literature. Russell et al. (2018) found that the use of a chosen name increased transgender individuals' mental well-being. Language certainly has a transformative power; it can both uphold societal oppression and assert identity. Moreover, it highlights the responsibility of cisgender people in deciding which of these two effects they will choose to adopt.

This participant-led research restructured the typical researcher-subject power dynamic present in many other methodologies. The auto-photography methodology was adopted to further participant autonomy and a written commentary was elicited, rather than interviews, to render a more anonymous and thoughtful process. Representation, therefore, was considered at all stages of the research process. Conversely, as this study recommended that the participants gave commentaries as long or as short as they wished, some responses were more open to thematic analysis than others. Some participants gave explanations of a few 
words long, whereas others found the commentary to be a resource for extensive reflection. Therefore, there may have been increased representation of those who engaged with the commentary. However, it was more important that each participant had authority to decide what and how much they participated within the study and this is considered to be a strength of this work.

Although seemingly a small sample size, the resultant themes can not and are not intended to be systematically generalised. To assume one true transgender experience is dangerous and could only further marginalise an already marginalised group. Rather, the purpose of this study was to explore and illustrate TGD student identity and present a view of their experiences that illuminate how the educational environment can reinforce social disaffirmation. Whilst this study was conducted by cisgender researchers (albeit including an insider researcher Dwyer \& Buckle, 2009), a fact that has previously been criticised on the basis that such researchers may fail to adequately represent real transgender experiences (Galupo, 2017), by utilising respondent validation the results formed a collaborative effort, vital in increasing representation and ensuring validity (Sparkes \& Smith, 2014). However, it is clear that there are always a multitude of factors which shape a person's experience. De Vries (2012) emphasised that the interplay of gender, race, social class and sexuality creates intersect with identity frames. These elements contribute to how the transgender persons view themselves, but according to De Vries (2012) current literature focuses broadly on while middle class transgender people only. To further the goals of this research, scholars must take an intersectional perspective.

With more people than ever accessing services for transgender heath care (Arcelus et al., 2015) and with growing recognition that not all transgender individuals wish to transition from one binary to the other, and differ in their medical wishes, there is an increasing need for healthcare providers to understand more deeply "what it is to be trans". More than a decade ago, Safer et al. (2017) reported that the biggest barrier to healthcare of transgender individuals was a lack of health providers who were adequately informed on transgender experiences and this has not changed greatly. This is concerning since many transgender individuals will resort to self-medication of hormones (Mepham et al., 2014; Whitehead, 2017) bought from the internet, that can be unsafe or undermine the efficacy of later treatment outcomes. Clearly there is a need for educational resources that encapsulate the many components contributing to the transgender experience. Further research of a similar nature could increase the global understanding of transgender people which may increase their quality of healthcare experience. This is particularly imperative considering not only the increase in those approaching the services, in addition to some transgender populations being disproportionately affected by serious conditions such as HIV (Safer et al., 2017) and difficulty in engaging with screening and care for gendered diseases such as prostate cancer (Kelly et al., 2018).

This research created a space for transgender young people to speak openly and frankly about their experiences and those things that serve to affirm or dis- 
affirm their gender. Documenting and understanding these things, alongside more quantitative, clinically-focused research that can drive positive changes in education and healthcare provision, is essential if scholars are to advocate for their participants.

\section{Conflicts of Interest}

There are no conflicts of interest to disclose. This study received no external funding.

\section{References}

Allen, M. P. (2010). Connecting Body and Mind: How Transgender People Changed Their Self-Image. Women and Performance: A Journal of Feminist Theory, 20, 267-283. https://doi.org/10.1080/0740770X.2010.529248

Arcelus, J., Bouman, W. P., Van Den Noortgate, W., Claes, L., Witcomb, G., \& Fernandez-Aranda, F. (2015). Systematic Review and Meta-Analysis of Prevalence Studies in Transsexualism. European Psychiatry, 30, 807-815. https://doi.org/10.1016/j.eurpsy.2015.04.005

Borba, R. (2017). Ex-Centric Textualities and Rehearsed Narratives at a Gender Identity Clinic in Brazil: Challenging Discursive Colonization. Journal of Sociolinguistics, 21, 320-347. https://doi.org/10.1111/josl.12236

Borba, R., \& Osterman, A. C. (2007). Do Bodies Matter? Travestis' Embodiment of (Trans)gender Identity through the Manipulation of the Brazilian Portuguese Grammatical Gender System. Gender and Language, 1, 131-147. https://doi.org/10.1558/genl.2007.1.1.131

Bouman, W. P., \& Arcelus, J. (2017). The Transgender Handbook: A Guide for Transgender People, Their Families and Professionals. New York: Nova Science Publishers.

Bouman, W. P., Schwend, A. M., Motmans, J., Smiley, A., Safer, J. D., Deutsch, M. B., Adams, N. J., \& Winter, S. (2016). Language and Trans Health. International Journal of Transgenderism, 18, 1-6. https://doi.org/10.1080/15532739.2016.1262127

Bradlow, J., Bartram, F., Guasp, A., \& Jadva, V. (2017). School Report: The Experiences of Lesbian, Gay, Bi and Trans Young People in Britain's Schools in 2017. London: Stonewall.

Braun, V., \& Clarke, V. (2006). Using Thematic Analysis in Psychology. Qualitative Research in Psychology, 3, 77-101. https://doi.org/10.1191/1478088706qp063oa

Butler, J. (1990). Gender Trouble. London: Routledge.

Davis, H. F. (2018). Why the Transgender Bathroom Controversy Make Us Rethink Sex-Segregated Public Bathrooms. Politics, Groups and Identities, 6, 199-216. https://doi.org/10.1080/21565503.2017.1338971

De Vries, K. (2012). Intersectional Identities and Conceptions of the Self: The Experience of Transgender People. Symbolic Interaction, 35, 49-67. https://doi.org/10.1002/symb.2

Dwyer, S. C., \& Buckle, J. L. (2009). The Space between: On Being an Insider-Outsider in Qualitative Research. International Journal of Qualitative Methods, 8, 54-63. https://doi.org/10.1177/160940690900800105

Effrig, J. C., Bieschke, K. J., \& Locke, B. D. (2011). Examining Victimization and Psychological Distress in Transgender College Students. Journal of College Counseling, 14, 143-157. https://doi.org/10.1002/j.2161-1882.2011.tb00269.x 
Frith, H., \& Harcourt, D. (2007). Using Photographs to Capture Women's Experiences of Chemotherapy: Reflecting on the Method. Qualitative Health Research, 17, 1340-1350. https://doi.org/10.1177/1049732307308949

Galupo, M. P. (2017). Researching While Cisgender: Identity Considerations for Transgender Research. International Journal of Transgenderism, 18, 241-242. https://doi.org/10.1080/15532739.2017.1342503

Glaw, X., Inder, K., Kable, A., \& Hazelton, M. (2017). Visual Methodologies in Qualitative Research: Autophotography and Photo Elicitation Applied to Mental Health Research. International Journal of Qualitative Methods, 16. https://doi.org/10.1177/1609406917748215

Harper, D. (1986). Meaning and Work: A Study in Photo Elicitation. Current Sociology, 34, 24-46. https://doi.org/10.1177/001139286034003006

Kelly, D., Sakellariou, D., Fry, S., \& Vougioukalou, S. (2018). Heteronormativity and Prostate Cancer: A Discursive Paper. Journal of Clinical Nursing, 27, 461-467. https://doi.org/10.1111/jocn.13844

Kenny, U., O’Malley-Keighran, M. P., Molcho, M., \& Kelly, C. (2017). Peer Influences on Adolescent Body Image: Friends or Foes? Journal of Adolescent Research, 32, 767-799. https://doi.org/10.1177/0743558416665478

Kosciw, J. G., Greytak, E. A., Giga, N. M., Villenas, C., \& Danischewski, D. J. (2016). The 2015 National School Climate Survey: The Experiences of Lesbian, Gay, Bisexual, Transgender, and Queer Youth in Our Nation's Schools. Gay, Lesbian and Straight Education Network (GLSEN). https://eric.ed.gov/?id=ED574780

Lovelock, M. (2016). Call Me Caitlyn: Making and Making over the "Authentic" Transgender Body in Anglo-American Popular Culture. Journal of Gender Studies, 6, 675-687. https://doi.org/10.1080/09589236.2016.1155978

MacNamara, J., Glann, S., \& Durlak, P. (2017). Experiencing Misgendered Pronouns: A Classroom Activity to Encourage Empathy. Teaching Sociology, 45, 269-278. https://doi.org/10.1177/0092055X17708603

McGuire, J. K., Mahan, D., Lacey, V., \& Hoelscher, M. C. (2017). Mental Health of Transgender Youth: The Role of Family, School, and Community in Promoting Resilience. St Paul, MN: University of Minnesota Extension. https://conservancy.umn.edu/bitstream/handle/11299/187823/mhtg-youth.pdf?sequen $\underline{\mathrm{ce}}=1$

Mckendry, S., \& Lawrence, M. (2017). The Place of Useful Learning TransEdu Scotland: Researching the Experience of Trans and Gender Diverse Applicants, Students and Staff in Scotland's Colleges and Universities.

http://www.trans.ac.uk/Portals/88/TransEdu-Scotland-Report-2017.pdf?ver=2017-10-0 3-124310-153

Mepham, N. J., Bouman, W. P., Arcelus, J., Hayter, M., \& Wylie, K. R. (2014). People with Gender Dysphoria Who Self-Prescribe Cross-Sex Hormones: Prevalence, Sources and Side Effects Knowledge. Journal of Sexual Medicine, 11, 2995-3001. https://doi.org/10.1111/jsm.12691

Meyer, I. H. (1995). Minority Stress and Mental Health in Gay Men. Journal of Health and Social Behavior, 36, 38. https://doi.org/10.2307/2137286

Miller, P. R., Flores, A. R., Haider-Markel, D. P., Lewis, D. C., Tadlock, B. L., \& Taylor, J. K. (2017). Transgender Politics as Body Politics: Effects of Disgust Sensitivity and Authoritarianism on Transgender Rights Attitudes. Politics, Groups, and Identities, 5, 4-24. https://doi.org/10.1080/21565503.2016.1260482 
Noland, C. M. (2006). Auto-Photography as Research Practice: Identity and Self-Esteem Research. Journal of Research Practice, 2, M1.

Nuttbrock, L., Bockting, W., Mason, M., Hwang. S., Rosenblum, A., Macri, M., \& Becker, J. (2011). A Further Assessment of Blanchard's Typology of Homosexual versus Non-Homosexual or Autogynephilic Gender Dysphoria. Archives of Sexual Behaviour, 40, 247-257. https://doi.org/10.1007/s10508-009-9579-2

Phoenix, C. (2010). Auto-Photography in Aging Studies: Exploring Issues of Identity Construction in Mature Bodybuilders. Journal of Aging Studies, 24, 167-180. https://doi.org/10.1016/j.jaging.2008.12.007

Pryor, J. T. (2015). Out in the Classroom: Transgender Student Experiences at a Large Public University. Journal of College Student Development, 56, 440-455. https://doi.org/10.1353/csd.2015.0044

Rankin, S., \& Beemyn, G. (2012). Beyond a Binary: The Lives of Gender-Nonconforming Youth. About Campus, 17, 2-10. https://doi.org/10.1002/abc.21086

Richards, C., Bouman, W. P., \& Barker, M. J. (2017). Genderqueer and Non-Binary Genders. Berlin: Springer. https://doi.org/10.1057/978-1-137-51053-2

Richards, C., Bouman, W. P., Seal, L., Barker, M. J., O’Neider, T., \& T’Sjoen, G. (2016). Non-Binary or Genderqueer Genders. International Review of Psychiatry, 28, 95-102. https://doi.org/10.3109/09540261.2015.1106446

Russell, S. T., Pollitt, A. M., Li, G., \& Grossman, A. H. (2018). Chosen Name Use Is Linked to Reduced Depressive Symptoms, Suicidal Ideation, and Suicidal Behaviour among Transgender Youth. Journal of Adolescent Health, 63, 503-505.

https://doi.org/10.1016/j.jadohealth.2018.02.003

Safer, J. D., Coleman, E., Feldman, J., Garofalo, R., Hembree, W., Radix, A., \& Sevelius, J. (2017). Barriers to Health Care for Transgender Individuals. Current Opinion in Endocrinology and Diabetes and Obesity, 23, 168-171. https://doi.org/10.1097/MED.0000000000000227

Seelman, K. L. (2014). Transgender Individuals' Access to College Housing and Bathrooms: Findings from the National Transgender Discrimination Survey. Journal of Gay \& Lesbian Social Services, 26, 186-206. https://doi.org/10.1080/10538720.2014.891091

Sevelius, J. M. (2012). Gender Affirmation: A Framework for Conceptualising Risk Behaviour among Transgender Women of Colour. Sex Roles, 58, 675-689. https://doi.org/10.1007/s11199-012-0216-5

Sparkes, A., \& Smith, B. (2014). Qualitative Research Methods in Sport, Exercise and Health. London: Routledge. https://doi.org/10.4324/9780203852187

Thorne, N., Witcomb, G. L., Nieder, T., Nixon, E., Yip, A., \& Arcelus, J. (2018). A Comparison of Mental Health Symptomatology and Levels of Social Support in Young Treatment Seeking Transgender Individuals Who Identify as Binary and Non-Binary. International Journal of Transgenderism, 20, 241-250.

Tobin, H. J., \& Levi, J. (2013). Securing Equal Access to Sex-Segregated Facilities for Transgender Students. Wisconsin Journal of Law, Gender and Society, 28, 301-330. http://digitalcommons.law.wne.edu/facschol

Vincent, B. W. (2018). Studying Trans: Recommendations for Ethical Recruitment and Collaboration with Transgender Participants in Academic Research. Psychology \& Sexuality, 9, 102-116. https://doi.org/10.1080/19419899.2018.1434558

Warren, J. C., Smalley, K. B., \& Barefoot, N. (2016). Psychological Well-Being among Transgender and Genderqueer Individuals. International Journal of Transgenderism, 17, 114-123. https://doi.org/10.1080/15532739.2016.1216344 
Whitehead, B. (2017) Inequalities in Access to Healthcare for Transgender Patients. Links to Health and Social Care, 2, 63-76.

Witcomb, G. L., Claes, L., Bouman, W. P., Motmans, J., Nixon, E., \& Arcelus, J. (2019). Experiences and Psychological Wellbeing Outcomes Associated with Bullying in Treatment-Seeking Transgender and Gender-Diverse Youth. LGBT Health, 6, 216-226. https://doi.org/10.1089/lgbt.2018.0179

Wolcott, H. F. (1994). Transforming Qualitative Data: Description, Analysis, and Interpretation. Thousand Oaks, CA: Sage Publications.

Ziller, R. (1990). Photographing the Self: Methods for Observing Personal Orientations. Newbury Park, CA: Sage. 